\title{
Diversity of dietary patterns observed in the European Prospective Investigation into Cancer and Nutrition (EPIC) project
}

\author{
N Slimani ${ }^{1, *}$, M Fahey ${ }^{1}$, AA Welch ${ }^{2}, E$ Wirfältt ${ }^{3}$, C Stripp $^{4}$, E Bergström ${ }^{5}$, J Linseisen ${ }^{6}$, \\ MB Schulze ${ }^{7}$, C Bamia $^{8}$, Y Chloptsios $^{8}$, F Veglia ${ }^{9}$, S Panico $^{10}$, HB Bueno-de-Mesquita ${ }^{11}$, \\ MC Ocké ${ }^{11}, M$ Brustad $^{12}$, E Lund ${ }^{12}$, CA González ${ }^{13}, \mathrm{~A} \mathrm{Barcos}^{14}, \mathrm{G} \mathrm{Berglund}^{3}$, \\ A Winkvist ${ }^{5}$, A Mulligan ${ }^{2}$, P Appleby ${ }^{15}$, K Overvad $^{16}$, A Tiønneland ${ }^{17}$, F Clavel- \\ Chapelon $^{18}$, E Kesse ${ }^{18}$, P Ferrari $^{1}$, WA Van Staveren ${ }^{19}$ and E Riboli ${ }^{1}$ \\ 'Unit of Nutrition and Cancer, International Agency for Research on Cancer, 150 cours Albert-Thomas, 69372 Lyon \\ Cedex 08, France: ${ }^{2}$ Institute of Public Health, University of Cambridge, UK: ${ }^{3}$ Department of Medicine, Surgery and \\ Orthopaedics, Lund University, University Hospital Malmö, Sweden: ${ }^{4}$ Institute of Cancer Epidemiology, Danish \\ Cancer Society, Copenhagen, Denmark: ${ }^{5}$ Epidemiology, Department of Public Health and Clinical Medicine, Umeå \\ University, Sweden: ${ }^{6}$ Division of Clinical Epidemiology, German Cancer Research Centre, Heidelberg, Germany: \\ ${ }^{7}$ German Institute of Human Nutrition, Potsdam-Rehbrücke, Germany: ${ }^{8}$ Department of Hygiene and Epidemiology, \\ School of Medicine, University of Athens, Greece: ${ }^{9}$ Institute for Scientific Interchange Foundation, Turin, Italy: \\ ${ }^{10}$ Department of Clinical and Experimental Medicine, University Federico II, Naples, Italy: " $D$ Department of Chronic \\ Diseases Epidemiology, National Institute for Public Health and the Environment, Bilthoven, The Netherlands: \\ ${ }^{12}$ Institute of Community Medicine, University of Tromsø, Norway: ${ }^{13}$ Department of Epidemiology, Catalan Institute \\ of Oncology, Barcelona, Spain: ${ }^{14}$ Service of Surveillance and Epidemiological Control, Institute of Public Health of \\ Navarra, Pamplona, Spain: ${ }^{15}$ Cancer Research UK, Epidemiology Unit, University of Oxford, UK: ${ }^{16}$ Institute of \\ Epidemiology and Social Medicine, University of Aarhus, Denmark: ${ }^{17}$ Institute of Cancer Epidemiology, Danish \\ Cancer Society, Copenhagen, Denmark: ${ }^{18}$ INSERM, U52 1, Institute Gustave Roussy, Villejuif, France: ${ }^{19}$ Department \\ of Human Nutrition and Epidemiology, Wageningen Agricultural University, The Netherlands
}

\begin{abstract}
Objective: To describe the diversity in dietary patterns existing across centres/regions participating in the European Prospective Investigation into Cancer and Nutrition (EPIC).

Design and setting: Single 24-hour dietary recall measurements were obtained by means of standardised face-to-face interviews using the EPIC-SOFT software. These have been used to present a graphic multi-dimensional comparison of the adjusted mean consumption of 22 food groups.

Subjects: In total, 35955 men and women, aged 35-74 years, participating in the EPIC nested calibration study.

Results: Although wide differences were observed across centres, the countries participating in EPIC are characterised by specific dietary patterns. Overall, Italy and Greece have a dietary pattern characterised by plant foods (except potatoes) and a lower consumption of animal and processed foods, compared with the other EPIC countries. France and particularly Spain have more heterogeneous dietary patterns, with a relatively high consumption of both plant foods and animal products. Apart from characteristics specific to vegetarian groups, the UK 'health-conscious' group shares with the UK general population a relatively high consumption of tea, sauces, cakes, soft drinks (women), margarine and butter. In contrast, the diet in the Nordic countries, The Netherlands, Germany and the UK general population is relatively high in potatoes and animal, processed and sweetened/refined foods, with proportions varying across countries/centres. In these countries, consumption of vegetables and fruit is similar to, or below, the overall EPIC means, and is low for legumes and vegetable oils. Overall, dietary patterns were similar for men and women, although there were large gender differences for certain food groups.

Conclusions: There are considerable differences in food group consumption and dietary patterns among the EPIC study populations. This large heterogeneity should be an advantage when investigating the relationship between diet and cancer and formulating new aetiological hypotheses related to dietary patterns and disease.
\end{abstract}

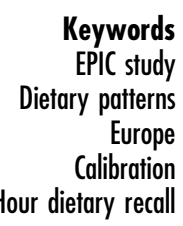

Keywords patterns Europe Calibration 24-Hour dietary recall 
Of all the environmental exposures diet is a universal exposure, comprising a complex mixture of different compounds that varies over time, space and according to a number of historical, ethnic, religious, agricultural, socioeconomic and psychological factors, at the individual and population levels ${ }^{1}$. The lack of unbiased dietary methods and the difficulty of measuring long-term individual cumulative dietary exposure, when measurements are obtained at fixed point(s) in time of the subject's life, are important methodological limitations for estimating diet accurately as an exposure ${ }^{2,3}$. These drawbacks may partly explain the lack of consistency in estimates of the association between diet and disease, particularly with regard to cancer ${ }^{4}$, and the attenuation in relative risk estimates of the actual relationship between diet and the outcome diseases due to random errors in dietary measurements ${ }^{5-7}$. Another emerging possible explanation, however, is that the methodologies used so far to analyse diet-disease relationships do not fully capture the nature and complexity of diet. For decades, the traditional practice has been to consider separately, in univariate analyses, the role of single foods, food groups or nutrients in relation to disease risk in order to distinguish their possible specific individual effects. The high intercorrelation between food (groups) and/or nutrient intakes and the difficulty of controlling for a number of possible dietary and other confounders in an analysis ${ }^{8-11}$ may, however, also partly explain the distortion in the estimates of the association observed between specific dietary components and cancer in particular ${ }^{12}$. In addition, current scientific evidence on carcinogenic mechanisms and the results from experimental and epidemiological studies suggest, for most cancers, multi-factorial causes involving several dietary and other factors, with possible synergetic or antagonist effects ${ }^{13}$.

These considerations have led to increased interest in multivariate or multi-dimensional analyses of so-called dietary patterns, which could better demonstrate that different foods and food groups are often consumed by individuals according to a reproducible pattern, despite large within- and between-subject variations ${ }^{14,15}$. Various statistical techniques (e.g. factor or cluster analysis) ${ }^{16}$ and other more innovative approaches ${ }^{17}$ exist and are now increasingly used for studying the association between dietary patterns and cancers and other chronic diseases ${ }^{18-22}$. Despite various methodological limitations (e.g. lack of stability and specificity of dietary patterns, and subjective selection of variables) ${ }^{16,23}$, this area of exploratory research opens promising perspectives for a better understanding of the relationship between dietary exposure and chronic diseases ${ }^{24,25}$.

The aim of this paper is to describe and highlight the diversity in dietary patterns existing across 27 centres/ regions participating in the European Prospective Investigation into Cancer and Nutrition (EPIC), using a graphic multi-dimensional comparison of the mean consumption of 22 common food groups obtained from highly standardised, computerised 24-hour dietary recall interviews.

\section{Materials and methods}

EPIC is a large cohort representing about half a million individuals in 10 Western European countries (Denmark, France, Germany, Greece, Italy, Norway, Spain, Sweden, The Netherlands and the UK) ${ }^{26}$. The choice of study populations was not intended to provide representative samples, but was determined by practical and logistical considerations to obtain high participation and long-term follow-up ${ }^{26}$. The study subjects were either populationbased (Bilthoven in The Netherlands, Greece, Germany, Sweden, Denmark, Norway, Spain, Italy, Cambridge and a small part of the Oxford cohort from the UK), participants in breast cancer screening (Utrecht in The Netherlands and Florence, Italy), or teachers and school workers in France. In Oxford, most of the cohort was recruited among subjects with an interest in health and/or vegetarian eating habits and were either self-defined vegans (i.e. consuming no animal products), ovo-lacto vegetarians, fish eaters (i.e. consumers of fish but not meat) or meat eaters. Blood donors were also recruited in different proportions in certain Italian and Spanish centres. In France, Norway, Utrecht (The Netherlands) and Naples (Italy) only women were recruited. Further details on the EPIC project are detailed elsewhere ${ }^{26}$.

Information on usual individual dietary intakes was obtained using different dietary assessment methods developed and validated in each participating country ${ }^{27-30}$. In order to adjust for possible systematic over- or underestimation in dietary intake measurements and correct for attenuation bias in relative risk estimates, a calibration approach was adopted. A single 24-hour dietary recall (24-HDR) was collected from a random sample of $5-12 \%$ (1.5\% in the UK) of the EPIC cohorts, weighted according to the cumulative numbers of cancer cases expected per fixed age and sex stratum ${ }^{31}$. Interviews were scheduled with the intention of obtaining an equal distribution of 24-HDRs according to day of the week and season.

The results presented in this paper are based on single 24-HDRs collected between 1995 and 2000 from 35955 subjects (13031 men and 22924 women) of the 36900 who participated in the calibration studies nested in the EPIC cohorts. The statistical analysis was restricted to subjects aged $35-74$ years; 945 subjects outside this range were excluded. In the UK, the 'health-conscious' group and the subjects recruited from the general population in both Cambridge and Oxford (general population group) were considered as two separate population groups. In France and Norway, where the study subjects were scattered all over the country, the groups were subdivided into, respectively, four and two geographical 
Table 1 Definitions and contents of the EPIC-SOFT food (sub-) groups considered in the analysis

\begin{tabular}{ll}
\hline Food group & \multicolumn{1}{c}{ Definition and content } \\
\hline Vegetables & Leafy, fruiting, root, grain, pod and stalk vegetables, mushroom, allium, cruciferous, sprouts \\
& and mixed salad/vegetables \\
Fruits & Fresh fruits, nuts, seeds, stewed fruit, mixed fruits and olives \\
Potatoes & Potatoes and potato products, except potato crisps \\
Legumes & Dried peas, lentils and beans, except soy \\
Cereals and cereal products & Flour, flakes, starches, pasta, rice and other grains, bread, crispbread, rusks, breakfast cereals, \\
& salty and aperitif biscuits, dough and pastry (puff, short-crust, pizza) \\
Cakes & Cakes, pies, pastries, puddings (non-milk-based), dry cakes, biscuits \\
Sugar and confectionery & Sugar, jam, marmalade, honey, chocolate and products, candy bars, confetti/flakes, drops, \\
& boiled sweets, chewing gum, nougat, cereal bars, marzipan, syrup, water ice \\
Added fats & Vegetable oils \\
Vegetable oils & Margarines, mixed dairy margarines, baking fat \\
Margarines & Butter, herbal butter, butter concentrate \\
Butter & Liquid milk (e.g. cow's, goat's), processed milk (condensed, dried), whey \\
Dairy products & Milk beverages, yoghurt, cheeses, cream desserts, puddings (milk-based), dairy creams, ice cream \\
Milk & Beef, veal, pork, lamb/mutton, horse, goat, poultry, game and offal \\
Dairy products & Processed meat from red meat or poultry (e.g. ham, bacon, sausages, pâtés, etc.) \\
Meat and meat products & Eggs (e.g. chicken, turkey, duck, goose, quail) and egg products, except if used for bread and \\
Fresh meat & bakery products \\
Processed meat & Fish and fish products, crustaceans and molluscs \\
Eggs & Tomato sauces, dressing sauces, mayonnaises and similars \\
Fish and shellfish & Tea (with and without caffeine), iced tea: infusion, powder, instant beverage \\
Sauces & Coffee (with and without caffeine): infusion, powder, instant beverage \\
Non-alcoholic beverages & Carbonated/soft/isotonic drinks, diluted syrups \\
Tea & Fruit and/or vegetable juices and nectars, freshly squeezed juices: pure or diluted with water \\
Coffee & Expressed as ethanol \\
Soft drinks &
\end{tabular}

regions. Consequently, results for 27 centres/regions are presented in this analysis. However, for convenience, the term 'centre' will be used to name both EPIC administrative centres and regions. Further details on the calibration study design and characteristics of the study participants are given elsewhere ${ }^{31}$.

Computerised 24-hour dietary recall interview software (EPIC-SOFT) was developed to assess dietary intakes reported across the EPIC centres in a standardised manner ${ }^{32,33}$. The same structure and translated interface were used in all 10 countries in order to standardise dietary interviews among the 90 interviewers involved in the calibration study. All of the 24-HDRs were collected during a face-to-face interview, except in Norway where the interviews were conducted by telephone ${ }^{34}$. Methods of quantification of portion sizes were standardised between countries using photographs, household measures depicted in pictures and standard units. For the telephone interviews, this material was mailed to the subjects in advance. Foods were classified according to the common EPIC-SOFT classification in 17 main groups and 124 subgroups.

All main groups of the EPIC-SOFT classification covering the different components of diet in all countries were considered in the analysis, except 'miscellaneous' and 'soups'. However, the groups 'dairy products' ('milk' and 'other dairy products'), 'meat and meat products' ('fresh meat' and 'processed meat'), 'non-alcoholic beverages' ('tea', 'coffee', 'soft drinks', 'fruit \& vegetable juices') and 'fat' ('vegetable oils', 'butter' and 'margarine') were considered at the sub-group level as indicated in brackets. Twenty-two main (sub-) groups of the common EPICSOFT classification were finally considered in this analysis (Table 1). These food groups were ordered according to their plant or animal origins and their degree of food processing to facilitate the comparison of dietary patterns across centres. For the comparison of alcoholic beverages, which vary greatly in type (e.g. beer, wine, spirits) and alcohol content across EPIC study centres ${ }^{35}$, we expressed alcohol consumption in grams of ethanol rather than millilitres of alcoholic beverages. Ethanol intake was computed using country-specific nutritional values.

The first purpose of the calibration study was to obtain good estimates of mean food intakes at the population level, and a single 24-HDR measurement was collected from each study participant. Our analysis is therefore focused on the comparison of mean dietary intakes. In order to compare dietary patterns across the 27 EPIC centres, crude and adjusted mean food consumption (g) for the $i$ th food group, $m(i)$, was calculated by sex and centre for each of the 22 food (sub-) groups. A standard multiple linear regression model was used to adjust for age, day of the week and season in order to correct for different distributions of these factors observed across the EPIC centres ${ }^{31}$. Total energy intake was also added to the model but, as this did not change the overall dietary 
patterns in most centres, these results are not reported here. Overall EPIC mean consumption, $M(i)$, was also calculated for the same food groups, by sex, as the arithmetic mean of the centre mean intakes. To express variation in centre mean intakes from the overall EPIC mean, percentage food intake relative to the EPIC mean was calculated for each food group, by sex and centre, as: $100 \% \times[m(i) / M(i)]$.

A multi-dimensional graphic representation of the relative food intakes is used to illustrate differences in dietary patterns by centre and gender; their corresponding values are provided in the Appendix. EPIC means, used as the common denominator to calculate deviations, are indicated in each figure by a reference circle of radius $100 \%$. If the relative consumption of a food group is above $100 \%$, it indicates that the given centre is characterised by a relatively high consumption of that food group compared with the reference EPIC mean, and vice versa when the relative intake is below $100 \%$. The same scale was used in the graphs for all countries and both genders (0-250\%). The end peaks of means exceeding 250\% are not reported in the graphs, but are indicated in the Appendix.

\section{Results}

\section{Italy}

In all Italian centres, diet is dominated by plant foods, particularly cereals and cereal products, fruits and vegetable oils, when compared with the EPIC means (Figs. 1a and 1b). In Varese, however, intake of vegetable oils was much lower than in the other centres. Several additional food groups characterise certain Italian centres and highlight further specific local dietary patterns. Legume consumption varies widely and is consistently much higher in women (except Turin) and in southern centres (Ragusa, Naples and Florence). Sauces, essentially tomato-based in these centres, are a strong characteristic of the diet in Ragusa and Varese for both genders but not in the other Italian centres, where consumption is around or below the EPIC mean. Alcohol is a characteristic of diet in men in Varese (124\%) and to a lesser degree in Turin in both genders, compared with the other centres. Whereas fresh meat consumption is about $10-20 \%$ higher than the EPIC mean in men from Varese and in women from Florence, Turin and Ragusa, it is closer to or below the EPIC mean elsewhere.

In contrast to fruit, vegetables are a relatively less important dietary characteristic in Italy, where consumption is around or below the EPIC mean, except in Turin $(\sim 135 \%)$ and to a lesser extent in Florence $(\sim 112 \%)$ in both genders. Consumption of potatoes is relatively low but similar across centres. Milk, butter and processed meat consumption is around or below the EPIC means and follows a geographical gradient, with $\sim 30 \%$ to $\sim 60 \%$ higher intakes in northern centres compared with southern centres, and vice versa for fish and eggs (in men). Coffee, tea, soft drinks and juices are consumed relatively rarely in most centres and margarines and butter (in southern centres) are not consumed.

\section{Greece}

The Greek diet is strongly characterised by plant food groups such as vegetable oils, legumes and vegetables in both genders, when compared with the EPIC means (Figs. $2 \mathrm{a}$ and $2 \mathrm{~b}$ ). In contrast to Italy and Spain, vegetable consumption is much higher than fruit consumption, with the latter below the EPIC mean in both genders. Consumption of cereal products is around the EPIC mean for both men and women. Consumption of animal products is around the mean for fish in men and below for fish in women, as are dairy products, fresh meat, eggs and milk for women. Alcohol (particularly among women), meat, juices, sugar products, cakes, soft drinks, potatoes and sauces and, to a greater extent, butter, coffee, margarine, processed meats and tea $(<30 \%)$ are not important components of the Greek diet, when compared with the EPIC means.

\section{Spain}

Spain has a complex dietary pattern characterised by a diet rich in both plant foods (legumes, vegetable oils, fruits and vegetables, except in Asturias) and animal food groups, particularly seafood, eggs and milk, but with important local variations (Figs. $3 \mathrm{a}$ and $3 \mathrm{~b}$ ). Consumption of legumes, fish and eggs are important dietary characteristics in all of the Spanish centres, but particularly in northern centres. Milk is consumed relatively highly all over Spain in women, but greater centre differences are observed in men. High consumption of fresh (and processed) meat and alcohol (in men) is more characteristic of northern centres. Potato consumption is within $\pm 10-15 \%$ of the EPIC mean, with $30-35 \%$ differences across centres. Consumption of cereal products, juices, soft drinks, cakes and sugar products is relatively low in all centres, except in Murcia where cake intake is around the EPIC mean. Tea, butter, margarine, coffee and sauces are not characteristic of the diet in any of the Spanish centres when compared with the EPIC means.

\section{France}

In France, the four large geographical regions cover the entire country, including inland, Atlantic and Mediterranean areas. However, the same main food groups (i.e. butter, dairy products, fresh meats, alcohol and, to a lesser extent, vegetables) characterise the diet in these regions compared with other EPIC centres, although with different orders of magnitude (Fig. 4). Butter consumption is higher in the North-west (290\%) and North-east (243\%) compared with the South (207\%) and South coast (167\%), and tea is consumed particularly in the North-west and South and to a lesser degree elsewhere. In contrast, consumption of dairy products, milk, eggs and fresh meat (except in the 
Diversity of EPIC dietary patterns
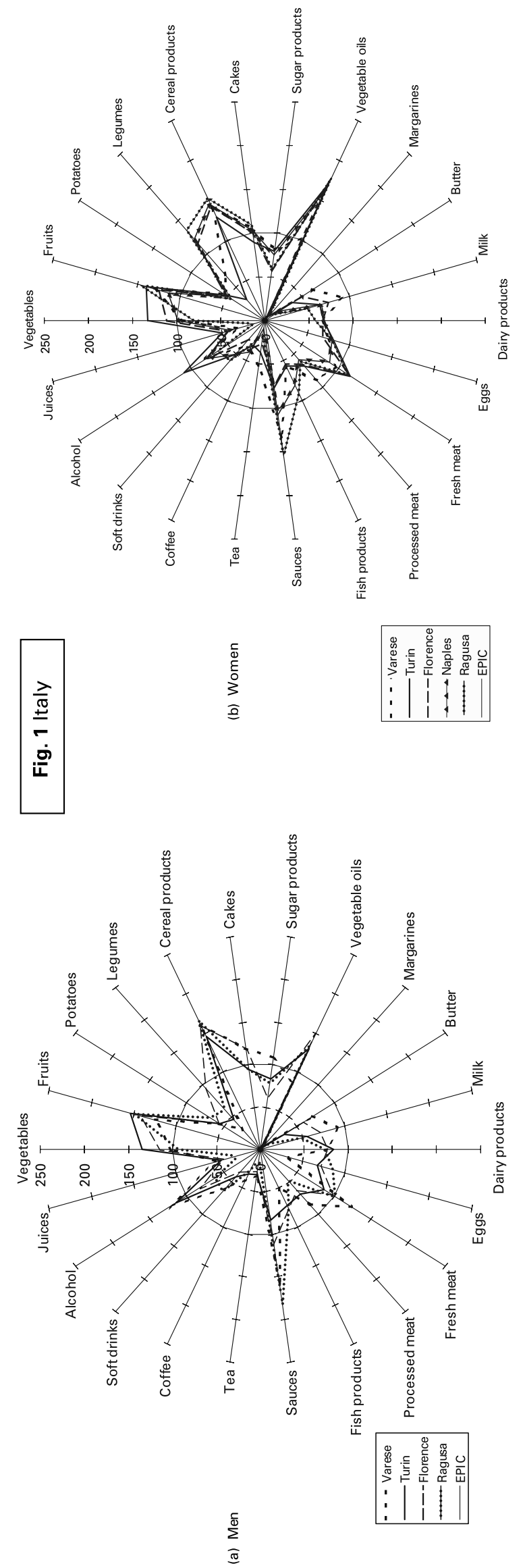

1315
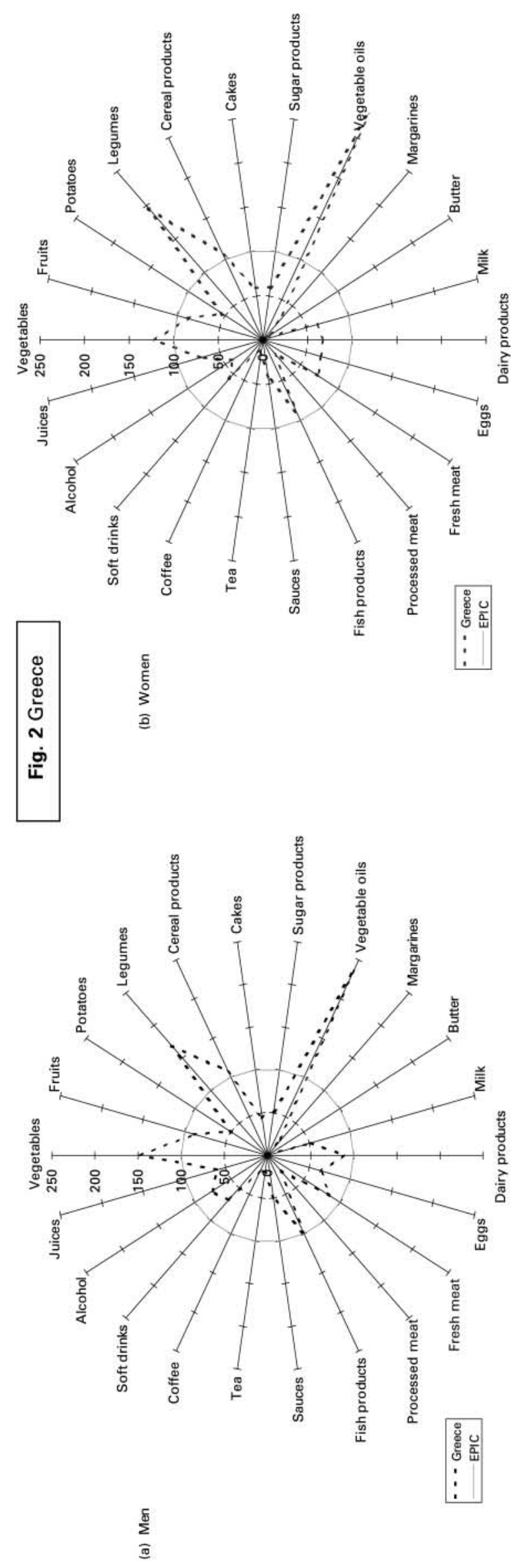

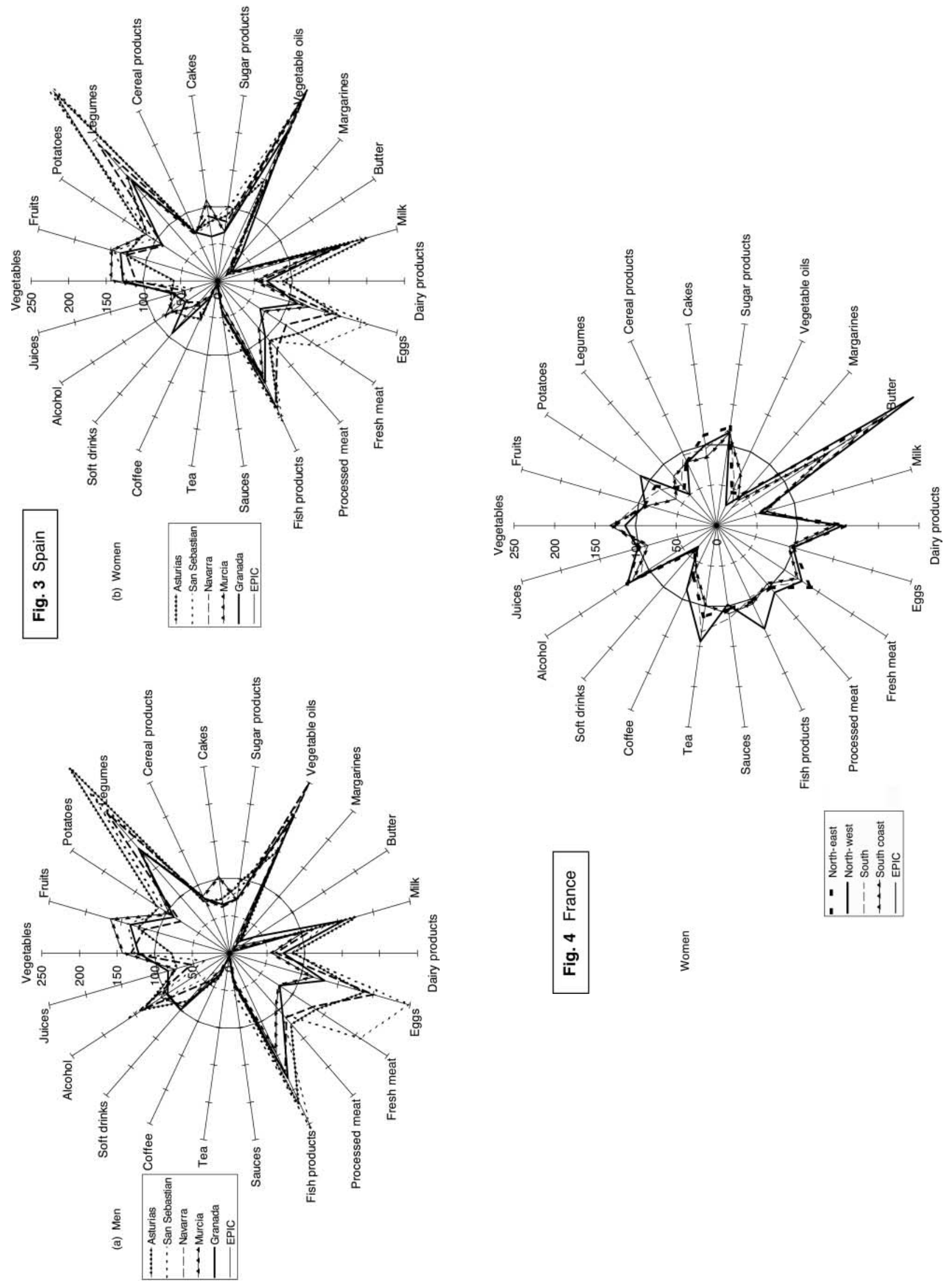

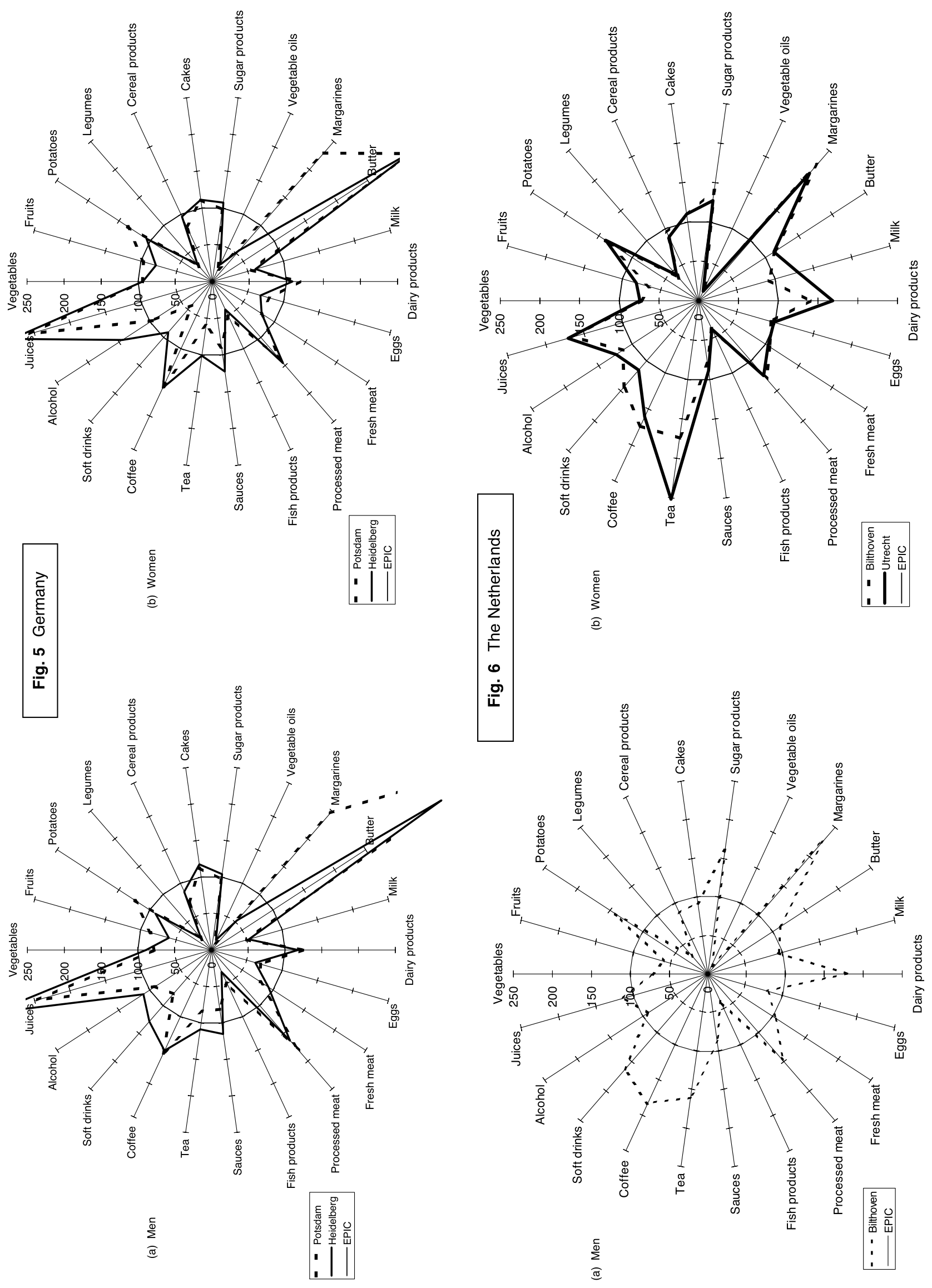

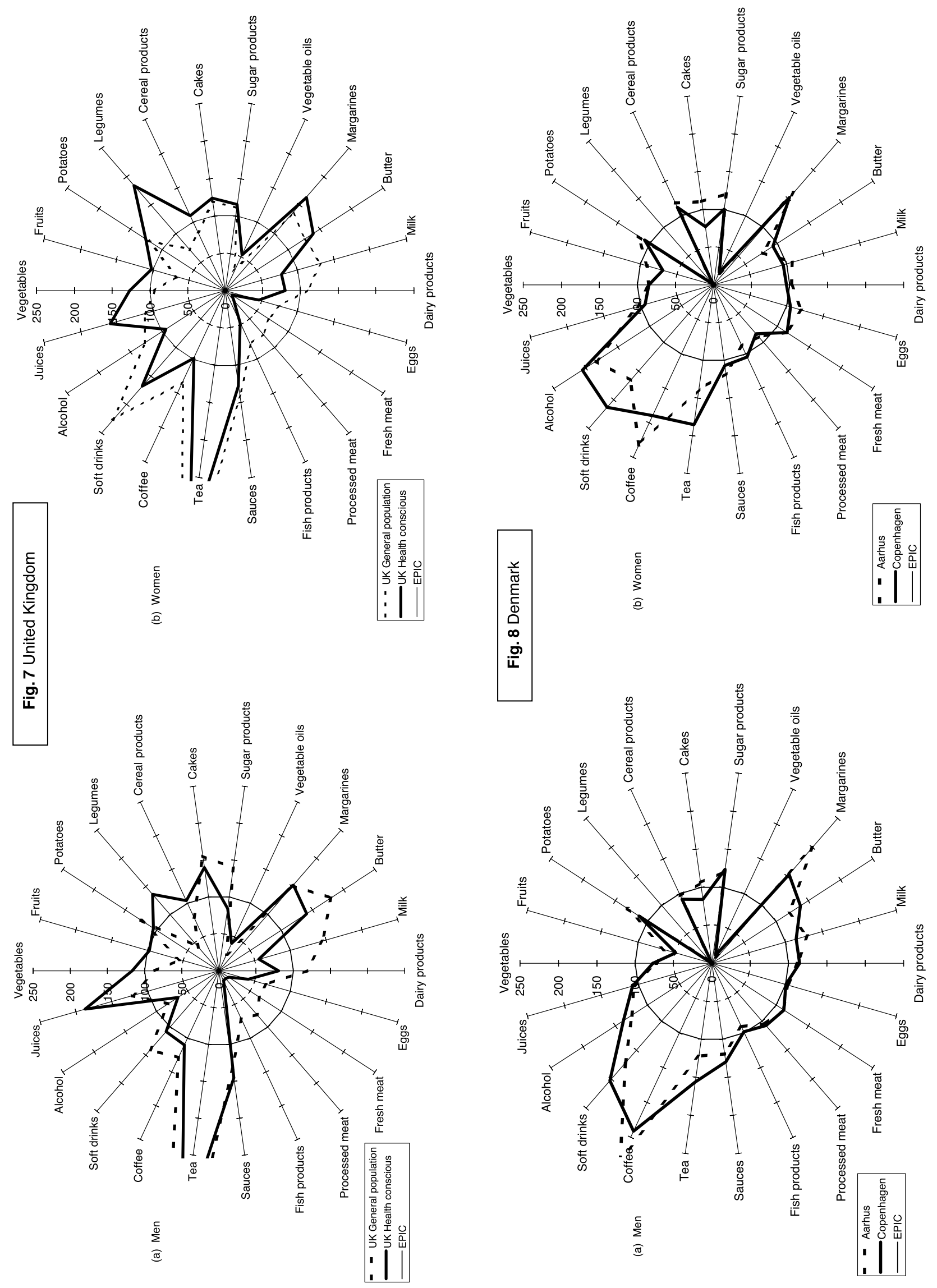

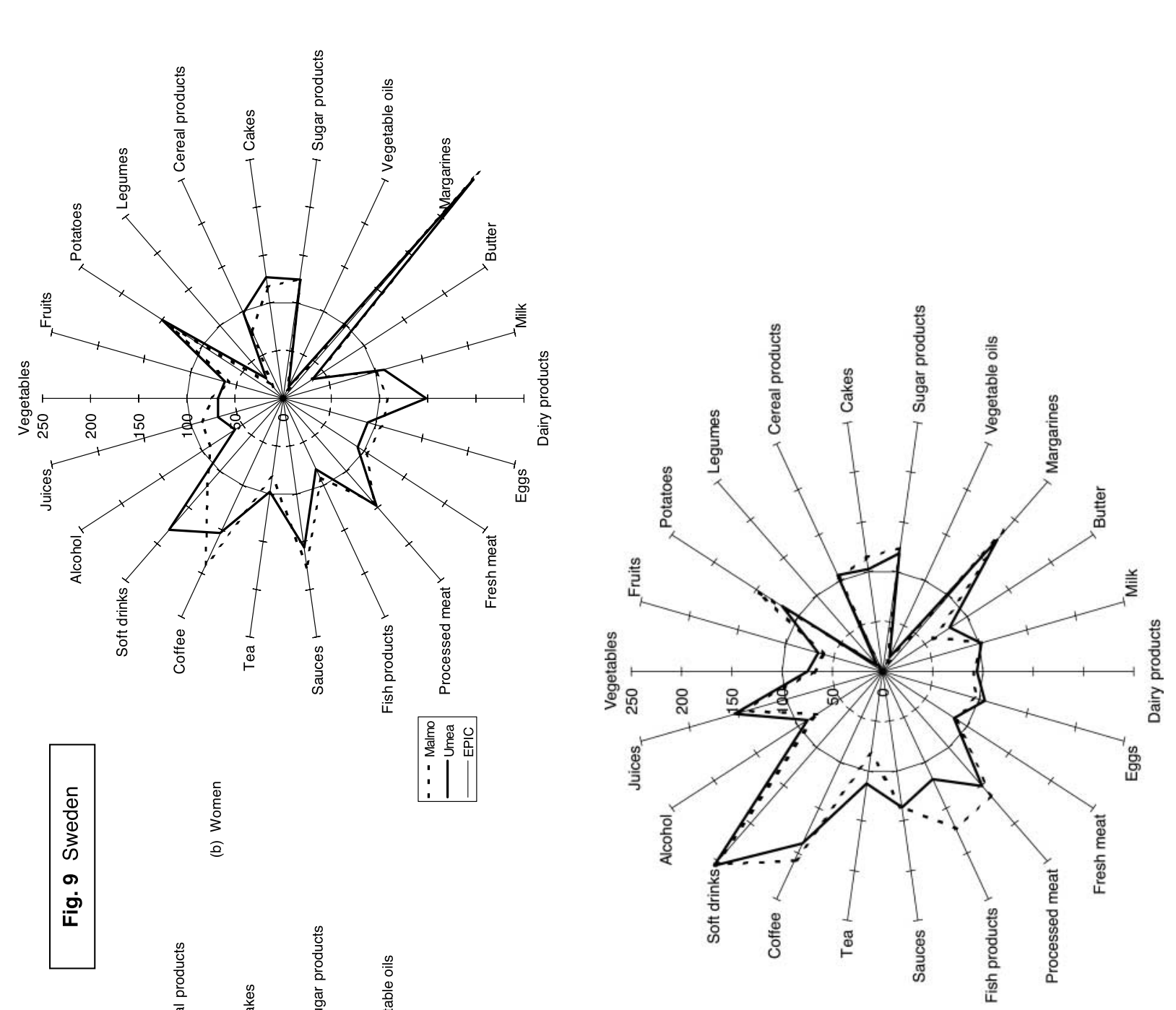

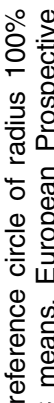

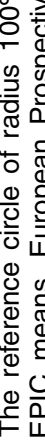

일
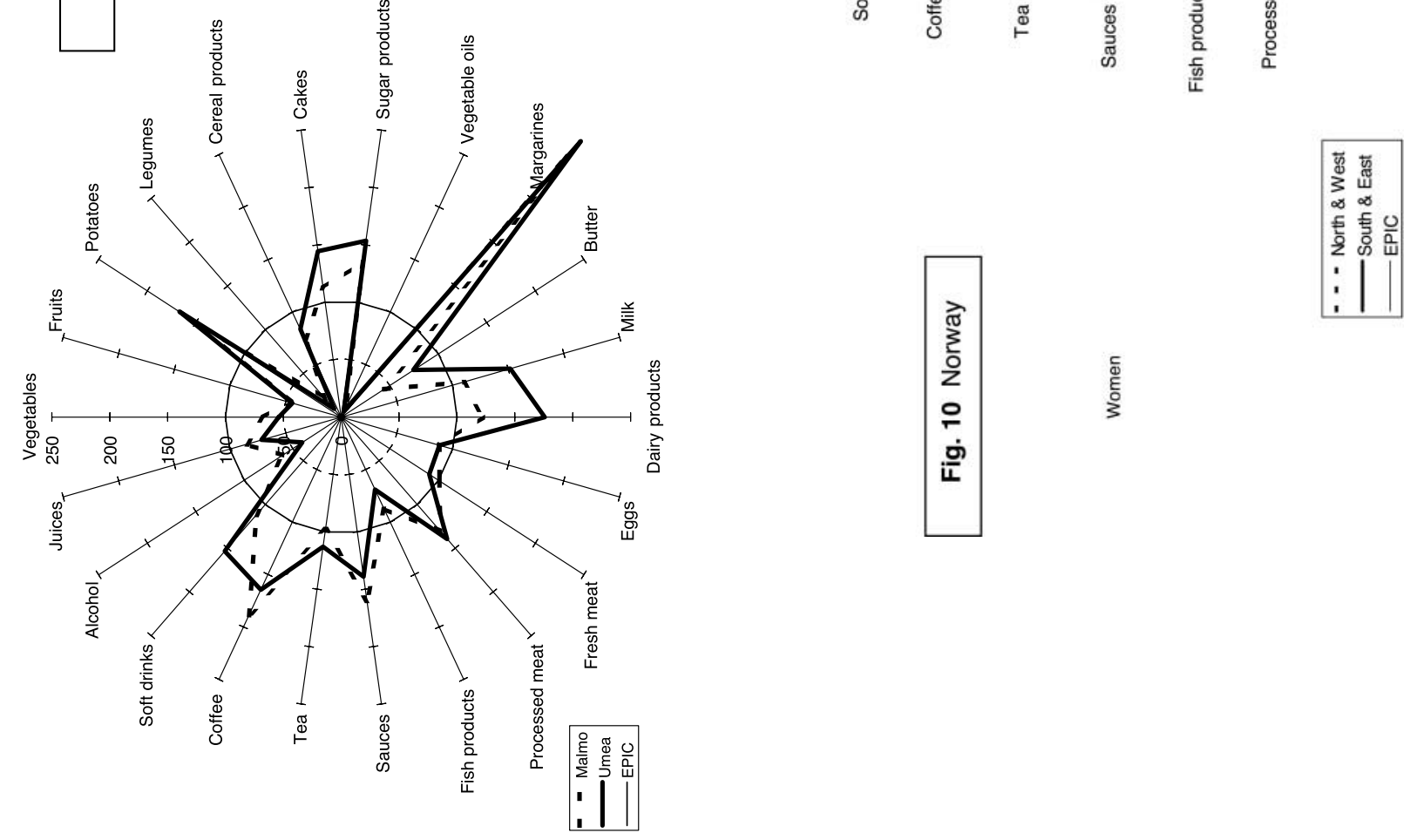

究

응 온

은 등

め

은 음 든 흔 ๓ 릉 윽 응 훙

응 음

항

ळ

듀ㅇㅝㅠ

离

$3 \%$
$\Phi$
0 
North-east, where it is higher) is quite similar across regions. Consumption of alcohol is about $25-30 \%$ above the EPIC mean, except in the South where it is lower than elsewhere in France. Fruit consumption is slightly below the EPIC mean whereas vegetable intake is higher in all regions (113-132\%). Fish products are an additional strong characteristic of the North-west region (140\%), but consumption is around the EPIC mean in the other regions.

Although consumption is around or below the EPIC mean, great variation ( $\geq 25 \%$ ) by regions is also observed for potatoes, vegetable oils, legumes, coffee, cakes and margarines, whereas consumption of processed meats, juices, fruits, sugar products, cereals and milk varies only from $8 \%$ to $15 \%$ by region. Soft drinks, margarine, milk and vegetable oils (except in the South) are the food groups consistently less consumed in France than in the other EPIC centres.

\section{Germany}

In both German centres, the same food groups characterise diet, i.e. butter, juices, followed by processed meat and coffee, with different orders of magnitude when compared with the EPIC means (Figs. 5a and 5b). Margarine is a further important characteristic of diet in Potsdam (formerly in East Germany) (>230\%) but not in Heidelberg $(<60 \%)$. To a lesser extent, potato consumption is greater in Potsdam than in Heidelberg, and vice versa for alcohol in women. Other food groups with lower relative consumption, such as soft drinks and sauces, show values $\geq 25 \%$ higher in Heidelberg than in Potsdam and inversely for fruits (men). Both centres are characterised by relatively low consumption of vegetable oils, legumes, fish products and milk.

\section{The Netherlands}

As the Utrecht cohort includes only women, no crosscentre comparison can be made for men between the two Dutch centres. The dietary pattern in The Netherlands is dominated by margarine, tea, coffee, dairy products, sugar products, potatoes, processed meats, juices (women) and soft drinks (men), with consumption $25-150 \%$ above the reference EPIC means (Figs. $6 \mathrm{a}$ and $6 \mathrm{~b}$ ). Except for butter and juices and alcohol in men, which are $10-15 \%$ above the EPIC means, all of the other food groups have a relative consumption around or below the EPIC mean. Marked differences are, however, observed among women, with higher values in Utrecht than in Bilthoven for tea, milk, dairy products and fruit, and vice versa for soft drinks and, to a lesser degree, sugar products, margarine and coffee. Vegetable oils, legumes, fish products and, to a lesser extent, vegetables and fruits (particularly in Bilthoven) are not typical of the Dutch diet.

\section{United Kingdom}

Various beverages (tea, soft drinks, and to a lesser extent, coffee and alcohol in women), butter, margarines, milk, sauces, cakes, potatoes and sugars (men) are major characteristics of the diet of the British general population when compared with the EPIC means (Figs. 7a and 7b). The consumption of juices and dairy products is about 10 $20 \%$ above the mean whereas for the other food groups it is around or below the EPIC means. Vegetable oils and legumes (men) and, to a lesser degree, fresh meat and fruits are food groups that are eaten in relatively smaller amounts by the British general population.

The British 'health-conscious' cohort includes a heterogeneous group of ovo-lacto vegetarians, pure vegans, fish (but not meat) eaters and meat eaters. The relatively low intake of animal products and the exclusive consumption of soy products ( $\geq 1600 \%$ deviation from the EPIC mean, value not reported), compared with the other centres, are the principal dietary characteristics of this population. Animal products such as fresh meat, processed meat, eggs and fish products are the food groups less representative of this population $(\leq 40 \%)$, although dairy products, milk and particularly butter (140\%) are consumed in greater amounts. As in Spain and Greece, a relatively high consumption of legumes is a characteristic of their diet, particularly in women (185\%), compared with the other EPIC centres, whereas vegetables and fruits are a relatively weak characteristic, but still $\sim 30-45 \%$ above consumption in the general population. Consumption of potatoes and cereal and cereal products is near the EPIC mean intake in men and $25 \%$ and $10 \%$ higher, respectively, in women. The relative consumption of alcohol is around the mean in women and more than $30 \%$ below in men. Fat intake comes mainly from margarines, butter (and sauces), all high markers of the health-conscious diet; vegetable oils, although more widely consumed than in the general British population, are not characteristic of the healthconscious diet, compared with the EPIC mean. The 'health-conscious' group differs from the general population for both sexes. Differences between the two group populations are large and range from $\sim 15 \%$ (e.g. sauces) to $\geq 1642 \%$ (soy products).

\section{Denmark}

In Denmark, coffee, soft drinks, alcohol, margarine and tea are primary characteristics of the diet when compared with the EPIC means, but with variations by sex and centre (Figs. 8a and 8b). Among men, consumption of sauces, sugars, potatoes and milk (only in Aarhus), and among women (from Aarhus only) eggs, cereals and cereal products, sauces, potatoes and sugar products, is about $20-30 \%$ above the mean. The Danish diet is also characterised by several other food groups with consumption around or $15 \%$ above the EPIC mean such as dairy products, fresh meats, milk, fish (Copenhagen) and eggs (except women in Aarhus). Consumption of most of the other food groups is below the EPIC means, particularly for vegetables and fruits (except women in 
Aarhus) and, to an even greater degree, for legumes and vegetable oil.

\section{Sweden}

In Sweden, margarine, sauces, coffee, potatoes, sugar products, processed meats and cakes dominate the diet in both centres and genders, but with different orders of importance by sex and centre, when compared with the EPIC means (Figs. 9a and 9b). Milk (men), dairy products and soft drinks are further strong specific characteristics of the diet in Umeå (152-181\%). Although consumed relatively less, coffee, sauces and juices have greater values in Malmö than in Umeå. All of the other groups have consumption around or below the sex-specific EPIC means with intakes varying across centres and genders. Consumption is particularly low for vegetable oils, legumes, butter and, to a lesser extent, fruits, vegetables and alcohol (Umeå).

\section{Norway}

The Norwegian cohort only included women. Soft drinks, coffee, margarine, processed meats, juices, sauces and, to a lesser extent, sugar products, characterise the diet in both regions (Fig. 10). Fish products (173\%) and potatoes (145\%) are further important markers of women's diet in the North \& West region, although consumption is still relatively high $(\sim 120 \%)$ in the South \& East region compared with the EPIC means. Intakes of milk, eggs, cereal and cereal products, dairy products and cakes (South \& East) are within $\pm 5-10 \%$ of the EPIC means in both centres, whereas intakes of most of the other food groups are below the EPIC means. Legumes, vegetable oils and, to a lesser extent, butter, fruit and vegetables are not characteristic of the Norwegian diet in either centre.

\section{Discussion}

The EPIC study was initiated in 1992 with the aim of combining several large European cohorts selected to maximise differences both in dietary exposure and disease outcome $^{36}$. The objective of this analysis was to describe and highlight the contrasts in dietary patterns observed across study centres, by comparing consumption of multiple food groups relative to the overall EPIC means. The comparison of absolute intakes across centres, which is discussed in detail elsewhere in this supplement ${ }^{35,37-43}$, was therefore not the main concern of our study.

Our analysis has led to a first major conclusion that large differences in dietary patterns exist between the 27 Western European centres participating in EPIC. Different types, numbers and magnitudes of consumption of food groups characterise these various dietary patterns. With few exceptions, we consistently observed that the number of food groups dominating the diet tends to increase from the Mediterranean dietary patterns observed, particularly in the Greek and Italian centres, to more or less pronounced Western dietary patterns observed elsewhere, with a strong south-north gradient within and between countries. Overall, we observed that in most of Western Europe, diets tended to be more heterogeneous than the Mediterranean diets, with a wider variety of food groups consumed; these are, however, essentially of animal origin or highly refined/processed, although exceptions and intermediate stages exist. However, the average total number of food items consumed per day is quite similar across centres $^{31}$. Further investigations on food choices, food consumption diversity and meal patterns will help us better to understand the differences in dietary patterns across the EPIC centres.

The analysis of the EPIC data presented here also showed that although considerable differences in diet were observed between centres, dietary patterns are markedly distinguishable from one country to another. Apart from the atypical UK 'health-conscious' population, which should be considered separately, the EPIC countryspecific dietary patterns can be classified broadly into three main categories.

Overall, Italy and Greece have different dietary patterns but both are characterised by plant foods (except potatoes), with a lower consumption of animal and processed foods than the other EPIC countries.

France and, to a greater degree, Spain have a more heterogeneous dietary pattern. The average Spanish diet, for example, is characterised by high consumption of both plant foods (legumes, vegetable oils, fruits and vegetables) and animal products such as fresh meat, eggs, processed meat, fish, milk and alcohol (men), but varies by centre and gender.

In contrast, the diet in the Nordic countries, The Netherlands, Germany and the UK general population was relatively high in potatoes and animal, processed and sweetened foods, with proportions varying across countries, indicating additional country- and centrespecific dietary patterns. Other common characteristics of these countries are that consumption of vegetables and fruit is about or below the overall EPIC means, and that legumes and vegetable oils are not typical of their diets.

The 'health-conscious' group in the UK reported an atypical diet different from that of the UK general and other EPIC populations. The diet is closer to Italy and Greece with respect to legumes, vegetables and fruits, but with lower consumption. In addition, soy products, which are not reported in this analysis, are consumed almost exclusively by this population group ${ }^{43}$. However, apart from characteristics associated with vegetarian eating habits, the UK 'health-conscious' group also exhibits a high consumption of tea, cakes, soft drinks, margarine and butter, as observed in the UK general population and other central and Nordic countries.

It is also interesting to note that the overall dietary patterns are similar between genders, although compared with different sex-specific EPIC means. However, the 
magnitude and ranking of relative food consumption across centres varied between genders for certain food groups. For example, we consistently observed a combined geographical/gender trend in alcohol consumption. In Spanish centres and Greece, the deviation from the sex-specific EPIC mean was consistently higher in men than in women for alcohol, and inversely in most of the other central and particularly Nordic centres.

Dietary patterns were similar when crude or adjusted means were used in the analysis, although adjustment for age, day of the week and season did affect the magnitude of the deviations from the EPIC means (data not shown). When total energy intake was added to the model, the overall patterns were very similar in most centres and genders, particularly for women (data not shown). However, greater differences were observed between the values obtained with the model that included total energy intakes and the one that did not, particularly in Greece, San Sebastian (Spain) and, to a lesser extent, Aarhus (Denmark) (women), suggesting a higher degree of underreporting or other possible factors. This is discussed in greater detail elsewhere in this supplement ${ }^{44}$.

These overall results must, however, be interpreted with caution as, even within food groups, considerable heterogeneity in consumption of products may exist across centres. For example, in our analysis we compared the average volume of coffee drunk across centres, independently of the active compounds contained and method of preparation. Further details on food items (e.g. expresso vs. filter coffee), redefinition of food groups and/ or composition or biomarker data would be required in order to study, for example, the consumption of caffeine and its association with diseases. In addition, the noninclusion of the food group 'soups' in this analysis means that consumption of vegetables or legumes (e.g. in Sweden) may have been underestimated, although this is unlikely to have affected the ranking of consumption across centres. Moreover, the data presented in this paper were obtained from individuals using a highly standardised methodology and the mean 24-HDR intakes should provide, in most centres, relatively reliable estimates at the EPIC population level.

However, the EPIC study cohorts are not designed to be representative of their countries; consequently extrapolation to general populations or to other studies should be made with caution. Furthermore, although other useful dietary data (e.g. food balance sheet or household budget survey data) for between-country comparisons exist ${ }^{45,46}$, they have several methodological limitations ${ }^{47}$, which means that no direct comparison can be made with individual estimates, particularly overall dietary patterns. Further work is needed to compare these different sources of dietary data.

This first overall analysis of EPIC data confirms a number of general trends in dietary patterns observed elsewhere. The Mediterranean centres involved in EPIC indirectly show an evolution in their traditional diets towards a more Western diet with different intermediate stages in Spain, France and the northern Italian centres. During the last 30-40 years, substantial changes in diet have been observed in both northern European and Mediterranean countries, reducing the differences traditionally existing between European dietary patterns ${ }^{48,49}$; the phenomenon is accelerating among younger generations $^{50-52}$. Over this period, Greece ${ }^{53}$ and more markedly Italy $^{54}$ and Spain ${ }^{55}$ have increased their consumption of animal products (i.e. meat, eggs, milk and dairy products) and decreased that of cereals while conserving some of the main features of their traditional Mediterranean diet (i.e. high consumption of fruits, vegetables, legumes, fish, olive oil), with even an increase in fruit and vegetable intakes.

Nordic and central European countries have also changed their different traditional diet to more Western diets. These changes are characterised particularly by a decrease in cereal and potato consumption and an increase in animal and processed foods ${ }^{56-58}$. For example, as suggested by the comparison of food supply data from the Food and Agriculture Organization for 1960-1990 ${ }^{58}$, they have also increased their consumption of meat in varying degrees, but less rapidly, as intake was already higher in the 1960s than in the Mediterranean countries (except France). It has been reported that diets in Nordic countries are healthier than in the past, due particularly to increased consumption of fruit and vegetables, although desirable intakes have not yet been reached ${ }^{59}$. These healthy changes were associated with the availability of an increased variety of foodstuffs, greater awareness due to public health programmes started in the early 1950s, and more openness to changes in diet ${ }^{60}$. Increased consumption of total vegetable oils, but not particularly of olive oil, was also observed in Nordic countries ${ }^{58}$, but this was essentially due to a substantial increase in margarine consumption in recent decades. However, the type of margarine consumed varies by centre, from pure vegetable margarine in Germany to high intakes of mixed-fat margarine (up to $70 \%$ of fat as dairy fat), particularly in Sweden and Denmark ${ }^{41}$.

\section{Conclusions}

This first multi-dimensional analysis of EPIC dietary data, using a common methodology, has confirmed that there are considerable differences in food group consumption and dietary patterns between the study populations. This heterogeneity should help to investigate the relationship between diet and cancer and to formulate new aetiological hypotheses related to overall dietary patterns and diseases. Put in perspective, our data add further indirect support to the observations that dietary patterns in Western societies are changing continuously and lead to the following recommendations for the future.

As other authors have stated ${ }^{61-64}$, there is a need to 
identify and better define or redefine the different variants of dietary patterns ${ }^{54,63-66}$ that deviate from the original Mediterranean diet as observed more than 40 years ago ${ }^{67}$, as well as the different forms of Western diets existing in Europe, as suggested by our data and others ${ }^{56,68-72}$.

These dietary changes and their determinants should be monitored over time with repeated measurements using a common methodology at the national and international level, with particular attention to younger generations.

As Willett ${ }^{73}$ has pointed out, a future challenging area of nutritional research is the analysis of dietary patterns and their association with chronic diseases, as the main dietary exposure or as a covariate, to control for confounding in univariate analyses considering one specific dietary component.

\section{Acknowledgements}

The work described in this paper was carried out with financial support of the 'Europe Against Cancer' Programme of the European Commission (SANCO); Ligue contre le Cancer (France); Société $3 \mathrm{M}$ (France); Mutuelle Générale de l'Education Nationale; Institut National de la Santé et de la Recherche Médicale (INSERM); Institute Gustave Roussy; German Cancer Aid; German Cancer Research Centre; German Federal Ministry of Education and Research; Danish Cancer Society; Health Research Fund (FIS) of the Spanish Ministry of Health; the Spanish Regional Governments of Andalucia, Asturias, Basque Country, Murcia and Navarra; Cancer Research UK; Medical Research Council, UK; Stroke Association, UK; British Heart Foundation; Department of Health, UK; Food Standards Agency, UK; Wellcome Trust, UK; Greek Ministry of Health; Greek Ministry of Education; Italian Association for Research on Cancer; Italian National Research Council; Dutch Ministry of Public Health, Welfare and Sports; Dutch Prevention Funds; LK Research Funds; Dutch ZON (Zorg Onderzoek Nederland); World Cancer Research Fund; Swedish Cancer Society; Swedish Scientific Council; Regional Government of Skane, Sweden; Norwegian Cancer Society; Norwegian Research Council. Partial support for the publication of this supplement was provided by the Centre de Recherche et d'Information Nutritionnelles (CERIN).

In addition, we wish to thank all study participants for their co-operation and all interviewers who participated in the fieldwork studies in each EPIC centre.

\section{References}

1 Murcott A. You are what you eat: anthropological factors influencing food choice. In: Ritson C, Gofon L, McKenzie J, eds. The Food Consumer. New York: John Wiley \& Sons Ltd, 1986.

2 Bingham SA. The dietary assessment of individuals; methods, accuracy, new techniques and recommendations. Nutr. Abstr. Rev. (Ser. A) 1987; 57: 705-42.
3 Archer VE. Cooking methods, carcinogens, and diet-cancer studies. Nutr. Cancer 1988; 11: 75-9.

4 Prentice RL. Measurement error and results from analytic epidemiology: dietary fat and breast cancer. J. Natl. Cancer Inst. 1996; 88: 1738-47.

5 Rosner B, Spiegelman D, Willett WC. Correction of logistic regression relative risk estimates and confidence intervals for random within-person measurement error. Am.J. Epidemiol. 1992; 136: 1400-13.

6 Willett WC. Nutritional Epidemiology, 2nd ed. New York: Oxford University Press, 1998.

7 Kipnis V, Midthune D, Freedman LS, Bingham S, Schatzkin A, Subar A, et al. Empirical evidence of correlated biases in dietary assessment instruments and its implications. Am. J. Epidemiol. 2001; 153: 394-403.

8 Ursin G, Ziegler RG, Subar AF, Graubard BI, Haile RW, Hoover R. Dietary patterns associated with a low-fat diet in the National Health Examination Follow-up Study: identification of potential confounders for epidemiologic analysis. Am. J. Epidemiol. 1993; 137: 916-27.

9 Weinberg CR. Toward a clearer definition of confounding [letter to the editor]. Am. J. Epidemiol. 1994; 140: 583-4.

10 Wu AH, Yang D, Pike MC. A meta-analysis of soyfoods and risk of stomach cancer: the problem of potential confounders. Cancer Epidemiol. Biomark. Prev. 2000; 9: 1051-8.

11 Klatsky AL. Diet, alcohol, and health: a story of connections, confounders, and cofactors. Am. J. Clin. Nutr. 2001; 74: 279-80.

12 Peto J. Cancer epidemiology in the last century and the next decade. Nature 2001; 411: 390-5.

13 World Cancer Research Fund/American Institute for Cancer Research (WCRF/AICR). Food, Nutrition and the Prevention of Cancer: A Global Perspective. Washington, DC: WCRF/ AICR, 1997.

14 Tarasuk V, Beaton GH. The nature and individuality of within-subject variation in energy intake. Am. J. Clin. Nutr. 1991; 54: 464-70.

15 Tarasuk V, Beaton GH. Day-to-day variation in energy and nutrient intake: evidence of individuality in eating behaviour? Appetite 1992; 18: 43-54.

16 Hair JF, Anderson RE, Tatham RL, Black WC. Multivariate Data Analysis with Readings. New York: Macmillan Publishing Co., 1992.

17 Ciampi A, Ferrari P, Slimani N, Overvad K, Ocké M, Wirfält E, et al. Discovering dietary patterns in nutritional epidemiology: towards a strategy integrating several techniques of multivariate analysis. Manuscript in preparation.

18 Huijbregts PPCW, Feskens EJM, Kromhout D. Dietary patterns and cardiovascular risk factors in elderly men: the Zutphen elderly study. Int. J. Epidemiol. 1995; 24: 313-20.

19 Slattery ML, Boucher KM, Caan BJ, Potter JD, Ma KN. Eating patterns and risk of colon cancer. Am. J. Epidemiol. 1998; 148: $4-16$

20 Hu FB, Rimm EB, Stampfer MJ, Ascherio A, Spiegelman D, Willett WC. Prospective study of major dietary patterns and risk of coronary heart disease in men. Am.J. Clin. Nutr. 2000; 72: $912-21$.

21 Palli D, Russo A, Decarli A. Dietary patterns, nutrient intake and gastric cancer in a high-risk area of Italy. Cancer Causes Control 2001; 12: 163-72.

22 Terry P, Suzuki R, Hu FB, Wolk A. A prospective study of major dietary patterns and the risk of breast cancer. Cancer Epidemiol. Biomark. Prev. 2001; 10: 1281-5.

23 Martinez ME, Marshall JR, Sechrest L. Factor analysis and the search for objectivity [invited commentary]. Am.J. Epidemiol. 1998; 148: 17-9.

24 Wirfält E, Mattisson I, Gullberg B, Berglund G. Food patterns defined by cluster analysis and their utility as dietary exposure variables: a report from the Malmö Diet and Cancer Study. Public Health Nutr. 2000; 3: 159-73. 
25 Jacques PF, Tucker KL. Are dietary patterns useful for understanding the role of diet in chronic disease? Am.J. Clin. Nutr. 2001; 73: 61-7.

26 Riboli E, Hunt KJ, Slimani N, Ferrari P, Norat T, Fahey M, et al. European Prospective Investigation into Cancer and Nutrition (EPIC): study populations and data collection. Public Health Nutr. 2002; 5(6B): 1113-24.

27 Tjønneland A, Overvad K, Haraldsdóttir J, Bang S, Ewertz M, Jensen OM. Validation of a semiquantitative food frequency questionnaire developed in Denmark. Int. J. Epidemiol. 1991; 20: 906-12

28 Bingham SA, Gill C, Welch A, Day K, Cassidy A, Khaw KT, et al. Comparison of dietary assessment methods in nutritional epidemiology: weighted records v. $24 \mathrm{~h}$ recalls, food-frequency questionnaires and estimated-diet records. Br.J. Nutr. 1994; 72: 619-43.

29 Riboli E, Elmståhl S, Saracci R, Gullberg B, Lindgärde F. The Malmö Food Study: validity of two dietary assessment methods for measuring nutrient intakes. Int. J. Epidemiol 1997; 26(Suppl. 1): S161-71

30 Margetts BM, Pietinen P, Riboli E, eds. EPIC: European Prospective Investigation into Cancer and Nutrition: validity studies on dietary assessment methods [special issue]. Int. J. Epidemiol. 1997; 26 (Suppl. 1): S1-189.

31 Slimani N, Kaaks K, Ferrari P, Casagrande C, ClavelChapelon F, Lotze $\mathrm{G}$, et al. European Prospective Investigation into Cancer and Nutrition (EPIC) calibration study: rationale, design and population characteristics. Public Health Nutr. 2002; 5(6B): 1125-45.

32 Slimani N, Deharveng G, Charrondière RU, van Kappel AL, Ocké MC, Welch A, et al. Structure of the standardized computerized 24-hour diet recall interview used as reference method in the 22 centers participating in the EPIC project. European Prospective Investigation into Cancer and Nutrition. Comput. Meth. Programs Biomed. 1999; 58: 251-66.

33 Slimani N, Ferrari P, Ocké M, Welch A, Boeing H, van Liere $\mathrm{M}$, et al. Standardization of the 24-hour diet recall calibration method used in the European Prospective Investigation into Cancer and Nutrition (EPIC): general concepts and preliminary results. Eur. J. Clin. Nutr. 2000; 54: 900-17.

34 Brustad M, Skeie G, Braaten T, Slimani N, Lund E. Comparison of telephone versus face-to-face interview in the assessment of dietary intake by the 24-hour recall EPICSOFT programme - the Norwegian calibration study. Eur. J. Clin. Nutr. 2002; in press.

35 Sieri S, Agudo A, Kesse E, Klipstein-Grobush K, San-José B, Welch A, et al. Patterns of alcohol consumption in 10 European countries participating in the European Prospective Investigation into Cancer and Nutrition (EPIC) project. Public Health Nutr. 2002; 5(6B): 1287-96.

36 Riboli E. Nutrition and cancer: background and rationale of the European Prospective Investigation into Cancer and Nutrition (EPIC). Ann. Oncol. 1992; 3: 783-91.

37 Agudo A, Slimani N, Ocké MC, Naska A, Miller AB, Kroke A, et al. Consumption of vegetables, fruit and other plant foods in the European Prospective Investigation into Cancer and Nutrition (EPIC) cohorts from 10 European countries. Public Health Nutr. 2002; 5(6B): 1179-96.

38 Hjartåker A, Lagiou A, Slimani N, Lund E, Chirlaque MD, Vasilopoulou E, et al. Consumption of dairy products in the European Prospective Investigation into Cancer and Nutrition (EPIC) cohort: data from 35955 24-hour dietary recalls in 10 European countries. Public Health Nutr. 2002; 5(6B): 1259-71.

39 Wirfält E, McTaggart A, Pala V, Gullberg B, Frasca G, Panico $S$, et al. Food sources of carbohydrates in a European cohort of adults. Public Health Nutr. 2002; 5(6B): 1197-215.

40 Linseisen J, Kesse E, Slimani N, Bueno-de-Mesquita HB, Ocké MC, Skiei G, et al. Meat consumption in the European Prospective Investigation into Cancer and Nutrition (EPIC) cohorts: results from 24-hour dietary recalls. Public Health Nutr. 2002; 5(6B): 1243-58.

41 Linseisen J, Bergström E, Gafá L, González CA, Thiébaut A, Trichopoulou A, et al. Consumption of added fats and oils in European Prospective Investigation into Cancer and Nutrition (EPIC) centres across 10 European countries as assessed by 24-hour recalls. Public Health Nutr. 2002; 5(6B): 122742.

42 Welch AA, Lund E, Amiano P, Dorronsoro M, Brustad M, Kumle M, et al. Fish consumption in 10 European countries participating in the European Prospective Investigation into Cancer and Nutrition (EPIC) study. Public Health Nutr. 2002; 5(6B): 1273-85.

43 Keinan-Boker L, Peeters PHM, Mulligan AA, Navarro C, Slimani N and the EPIC Study Group on Soy Consumption. Soy product consumption in 10 European countries: the European Prospective Investigation into Cancer and Nutrition (EPIC) study. Public Health Nutr. 2002; 5(6B): 1217-26.

44 Ferrari P, Slimani N, Ciampi A, Trichopoulou A, Naska A, Lauria $\mathrm{C}$, et al. Evaluation of under- and overreporting of energy intake in the 24-hour diet recalls in the European Prospective Investigation into Cancer and Nutrition (EPIC). Public Health Nutr. 2002; 5(6B): 1329-45.

45 Food and Agriculture Organization (FAO). Food Balance Sheets [online]. Available at http://apps.fao.org/lim500wrap. pl?FoodBalanceSheet $\&$ Domain $=$ FoodBalanceSheet $\&$ Language=english. Rome: FAO, 2001.

46 University of Athens. DafneSoft (DAta Food NEtworking) [online]. Available at http://www.nut.uoa.gr. Athens: School of Medicine, Public Health and Nutritional Epidemiology Unit, 2001.

47 Serra-Majem L. Food availability and consumption at national, household and individual levels: implications for food-based dietary guidelines development. Public Health Nutr. 2001; 4: 673-6.

48 Hill MJ. Changing pattern of diet in Europe. Eur. J. Cancer Prev. 1997; 6(Suppl. 1): S11-3.

49 Rumm-Kreuter D. Comparison of the eating and cooking habits of Northern Europe and the Mediterranean countries in the past, present and future. Int.J. Vitam. Nutr. Res. 2001; 71: $141-8$.

50 Amorim Cruz JA. Dietary habits and nutritional status in adolescents over Europe - Southern Europe. Eur. J. Clin. Nutr. 2000; 54(Suppl. 1): S29-35.

51 Rolland-Cachera MF, Bellisle F, Deheeger M. Nutritional status and food intake in adolescents living in Western Europe. Eur. J. Clin. Nutr. 2000; 54(Suppl. 1): S41-6.

52 Samuelson G. Dietary habits and nutritional status in adolescents over Europe. An overview of current studies in the Nordic countries. Eur. J. Clin. Nutr. 2000; 54(Suppl. 1): S21-8.

53 Simopoulos AP, Sidossis LS. What is so special about the traditional diet of Greece. World Rev. Nutr. Diet. 2000; 87: $24-42$.

54 Ferro-Luzzi A, Branca F. Mediterranean diet, Italian-style: prototype of a healthy diet. Am. J. Clin. Nutr. 1995; 61(Suppl.): S1338-45.

55 Serra-Majem L, Santana-Armas JF, Salmona E. Dietary habits and nutritional status in Spain. World Rev. Nutr. Diet. 2000; 87: $127-59$.

56 Trygg K. Food patterns in Nordic countries. Ann. Nutr Metab. 1991; 35(Suppl. 1): 3-11.

57 Oshaug A. Historical perspective and problem analysis of nutrition security in Norway. Is nutrition security in Norway? A situation analysis. Scand. J. Nutr. 1994; 28(Suppl.): 6-29.

58 Helsing E. Trends in fat consumption in Europe and their influence on the Mediterranean diet. Eur.J. Clin. Nutr. 1993; 47(Suppl. 1): S4-12.

59 Johansson L, Drevon CA, Bjørneboe G-EA. The Norwegian 
diet during the last hundred years in relation to coronary heart disease. Eur. J. Clin. Nutr. 1996; 50: 277-83.

60 De Graaf C, Van der Gaag M, Kafatos A, Lennernas M, Kearney JM. Stages of dietary changes among nationally representative samples of adults in the European Union. Eur. J. Clin. Nutr. 1997; 51(Suppl. 2): S47-56.

61 Ferro-Luzzi A, Sette S. The Mediterranean diet: an attempt to define its present and past composition. Eur. J. Clin. Nutr. 1989; 43: 13-29.

62 Helsing E. Traditional diets and disease patterns of the Mediterranean, circa 1960. Am. J. Clin. Nutr. 1995; 61(Suppl.): S1329-37.

63 Simopoulos AP. The Mediterranean diets: what is so special about the diet of Greece? The scientific evidence. J. Nutr. 2001; 131: S3065-73.

64 Noah A, Truswell AS. There are many Mediterranean diets. Asia Pacific J. Clin. Nutr. 2001; 10: 2-9.

65 Kafatos A, Verhagen H, Moschandreas J, Apostolaki I, Van Westerop JJ. Mediterranean diet of Crete: foods and nutrient content. J. Am. Diet. Assoc. 2000; 100: 1487-93.

66 Moreiras O, Cuadrado C. Mediterranean diet and lifestyle: special aspects of Spain. Int. J. Vitam. Nutr. Res. 2001; 71 : $154-8$.
67 Keys A, ed. Seven Countries: A Multivariate Analysis of Death and Coronary Heart Disease. Cambridge, MA: Harvard University Press, 1980.

68 Hulsholf KFA, Wedel M, Löwik MRH, Kok FJ, Kistemaker C, Hermus RJJ, et al. Clustering of dietary variables and other lifestyle factors (Dutch Nutritional Surveillance System). J. Epidemiol. Community Health 1992; 46: 417-24.

69 SENECA Investigators. Food patterns of elderly Europeans. Eur. J. Clin. Nutr. 1996; 50(Suppl. 2): S86-100.

70 Winkler G, Brasche S, Döring A, Heinrich J. Dietary intake of middle-aged men from an East and West German city after the German reunification: do differences still exist? Eur. J. Clin. Nutr. 1998; 52: 98-103.

71 Vlatier JL, Verger P. Recent national French food and nutrient intake data. Br. J. Nutr. 1999; 81(Suppl. 2): S57-9.

72 Pryer JA, Nichols R, Elliott P, Thakrar B, Brunner E, Marmot M. Dietary patterns among a national random sample of British adults. J. Epidemiol. Community Health 2001; 55 : $29-37$.

73 Willett WC. Nutritional epidemiology issues in chronic disease at the turn of the century. Epidemiol. Rev. 2000; 22: 82-6. 


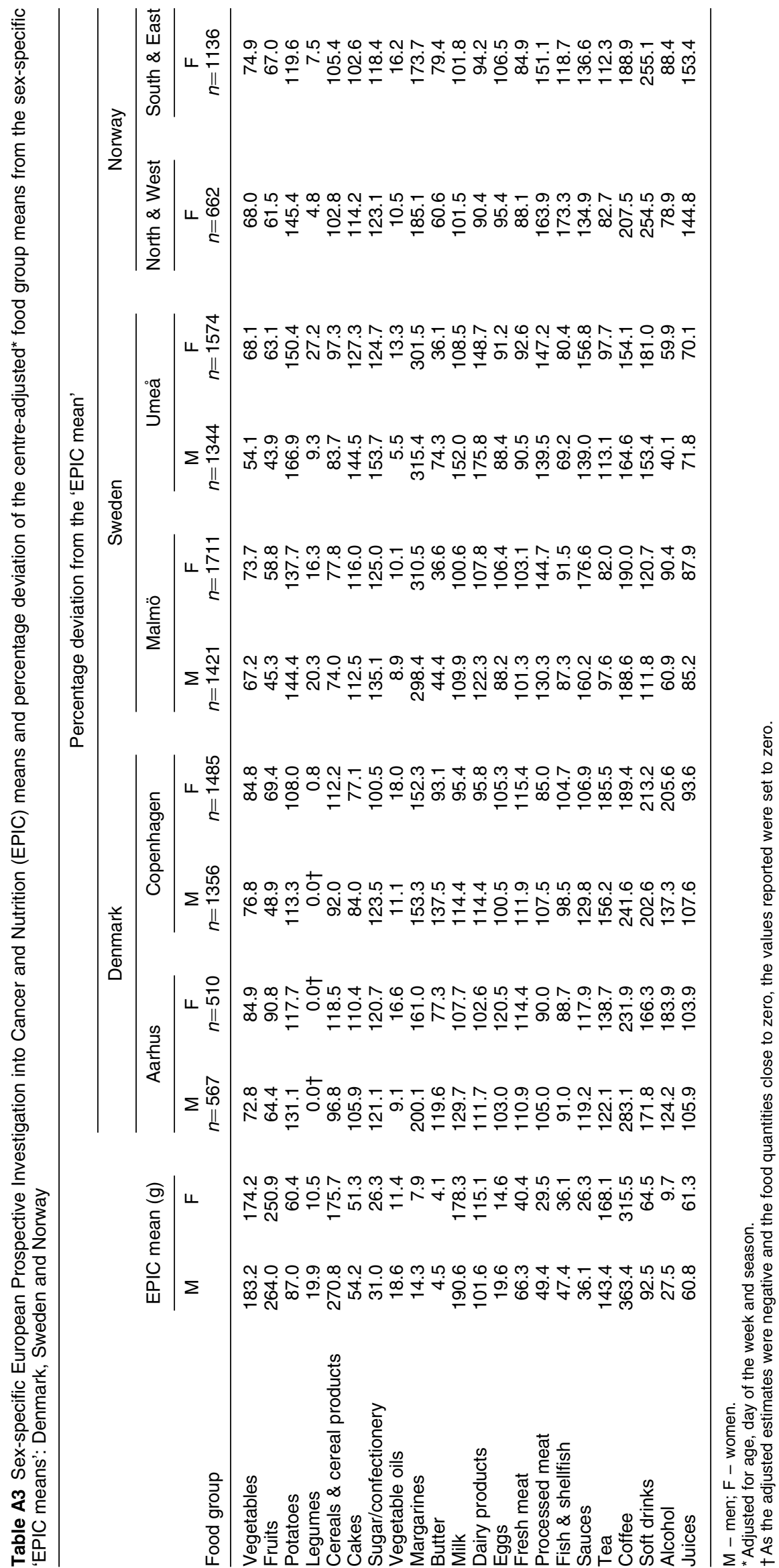

